Research Article

Sara Ahmed, Tao Meng*, and Mazahir Taha

\title{
Utilization of red mud for producing a high strength binder by composition optimization and nano strengthening
}

https://doi.org/10.1515/ntrev-2020-0029

Received November 11, 2019; accepted November 29, 2020

Abstract: Recycling of red mud (RM) has attracted more attention in recent years due to severe environmental problems caused by landfilling. The effect of composition optimization and Nano-strengthening on the properties of a binder based on RM was studied in this paper. Results showed that modifying ratios of main oxides and adding Nano- $\mathrm{SiO}_{2}$ could obviously affect the mechanical properties and microstructure of the binder. Specimens with high $\mathrm{SiO}_{2} / \mathrm{Al}_{2} \mathrm{O}_{3}$ molar ratio (S/A) displayed considerable increase in compressive strength, while decreasing $\mathrm{Na}_{2} \mathrm{O} / \mathrm{Al}_{2} \mathrm{O}_{3}$ molar ratio (N/A) improved the workability of the fresh mix. The compressive strength was developed significantly to be $45 \mathrm{MPa}$ at 28 days by adding $\mathrm{Nano}^{-\mathrm{SiO}_{2}}$ with 0.4 wt.\% of RM. Phase transformation and microstructure change at different stages of RM decomposition and binder geopolyerization were investigated by X-ray diffraction (XRD), Fourier transformation infrared (FTIR) and Scanning electron microscopy (SEM). The results of this study may provide a prospective method to use RM more widely in construction applications.

Keywords: red mud binder; composition optimization; nano strengthening; compressive strength; nano silica

Corresponding Author: Tao Meng, College of Civil Engineering and Architecture, Zhejiang University, Hangzhou 310058, China; e-mail: taomeng@zju.edu.cn

Sara Ahmed: College of Civil Engineering and Architecture, Zhejiang University, Hangzhou 310058, China

Mazahir Taha: School of Civil Engineering, Northeast Forestry University, Harbin 150040, China

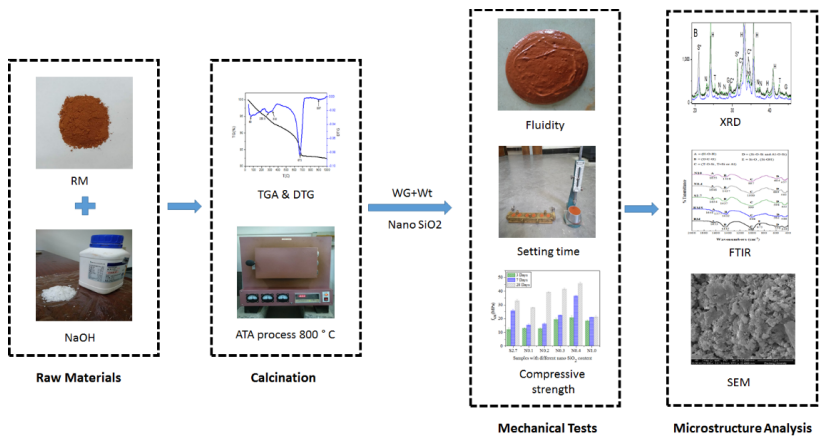

Graphical abstract

\section{Introduction}

RM is the main by-product for extracting alumina from bauxite ore using Bayer process. Producing one ton of aluminium may cause ejection of 2 to 4 tons of RM [1]. The growing need for aluminium led to an annual global production of RM between 70-120 million tons. As a result, large quantities of RM accumulated to reach 2.7 billion tons worldwide [2].

The chemical composition of RM depends mainly on the type of bauxite ore $[3,4]$ and the different processes of alumina production $[5,6]$, therefore, RM consists of many oxides such as $\mathrm{SiO}_{2}, \mathrm{Al}_{2} \mathrm{O}_{3}, \mathrm{Fe}_{2} \mathrm{O}_{3}$ and $\mathrm{CaO}$ [7]. The $\mathrm{RM}$ acquires its high alkalinity as a result of using sodium hydroxide during the alumina extraction process [1] and the $\mathrm{pH}$ value ranges from 10.3 to 12.3 [8]. Plus, RM may contain some toxic metals such as lead, nickel and zinc depending on the source of bauxite ore [9].

In the past years, the aluminium producing companies adopted landfilling (Lagoons and dry stacks) and marine discharge to dispose RM [10]. Mentioned methods are adversely affecting the environment because of RM harmful properties such as toxicity and alkalinity [2, 11]. By continue discharging RM into lagoons, disasters such as that happened in Ajka, Hungary 2010 (Kolontar disaster) and Henan, China 2016 may recur [12]. Leaching of toxic heavy metals and high alkaline slurry of RM into the ground causes groundwater contamination [13] and affects plants.

๖ Open Access. @ 2020 Sara Ahmed et al., published by De Gruyte 
Besides, inhalation of RM dust is considered as a severe environmental problem [14].

Recently, several studies have been conducted to obtain effective and safe methods for utilization and reuse of $\mathrm{RM}$ to avoid annual accumulation [15]. There are some important uses like wastewater treatment $[1,16]$, toxic metal removal [7, 17], and recovery of metals [18]. Regardless the mentioned uses, the Aluminium association adduced that $\mathrm{RM}$ use rate is meager compared to the annual production rate [1]. Klauber et al. mentioned that despite studies and researches have been done through the last years, there is insufficient evidence for using RM effectively [19]. For example, in China the annual production is $30 \mathrm{Mt}$ which is approximately $30 \%$ of the total world production, but only $4 \%$ of this quantity is actually be reused [20]. Utilization of RM in a practical way is facing several challenges [7], such as its ability to compete against alternative materials regarding quality, cost and safety. Add to that the variation in chemical composition of RM is considered as an obstacle for obtaining an optimal mixing structure, such as low $\mathrm{Si} / \mathrm{Al}$ ratio which may result in weak characteristics of the product [21, 22]. Moreover, the non-standard RM properties obstruct the necessary transaction costs such as disposal management cost or pretreatment cost [19]. As well, the risk of alkalinity and toxicity limits the possibility of using RM effectively [8].

However, uses in construction field pull considerable attention [14, 23, 24]. RM has been used in building materials such as Glass-ceramic, ceramic pigments, ceramic foam [25-29], fire resistant building materials [10], cement and block production [24, 30-33]. RM also has been mixed with other materials like fly ash, metakaolin and blast furnace slag to produce geopolymer, a term coined by Davidovits [34] to describe the output of inorganic materials rich with $\mathrm{SiO}_{4}$ and $\mathrm{AlO}_{4}$ and activated by alkaline solutions [35]. Geopolymer is considered as a prospective method to utilize RM and other industrial by-products to replace cement for its good performance and low $\mathrm{CO}_{2}$ emissions during its manufacture $[36,37]$. The characteristics of geopolymer depend on several factors including chemical compositions of source materials, curing conditions and alkali activator type and concentration [38, 39]. Choo et al. noticed an increase of unconfined compressive strength (UCS) of fly ash when RM used as an alkali supplier [40]. Chen et al. observed the ability of RM to adsorb heavy metal ions for granulated blast furnace slag geopolymer [41]. Zhang et al. stated a satisfying result of RM-FFA geopolymer compared to ordinary Portland cement regarding resistance of sulfuric acid [9]. Ye et al. used considerable quantities of RM after been treated by Alkali Thermal
Activation (ATA) and mixed with silica fume to produce one-part geopolymer [42, 43].

On the other hand, the effect of RM characteristics on geopolymer is not satisfactory, as the mechanical properties of the binder deteriorated when the ratio between RM and other materials increased [44]. He et al. mentioned that lower RM/FA ratio generated a positive effect of mechanical properties of geopolymer, while higher RHA/RM ratio led to higher ductility, stiffness and strength [45, 46]. Hajjaji et al. reported that the samples with a low amount of RM recorded high compressive strength [21]. Hairi et al. produced geopolymer with significantly low strength by using red mud [47]. In a comparative study, He et al. stated that the strength of MK is higher than RM-FA mixture [48].

Weak points of RM emerged by previous researches are considered as a strong motivation for further studies about $\mathrm{RM}$ and its utilization as a construction material. In this research one of the main objectives is to use RM as much as possible, and try to use RM to produce a binder with acceptable strength. So, the RM was used as the main solid material. Alkali Thermal Activation process was applied on raw RM to help improve its properties [42, 43, 49], and the chemical compositions of the mix were modified to get the optimum ratios for producing the binder.

The $\mathrm{Nano} \mathrm{SiO}_{2}$ was used in different fields [50-52]. In this research the Nano- $\mathrm{SiO}_{2}$ was added to suitable composition mix to augment the compressive strength. The Nano$\mathrm{SiO}_{2}$ stimulates forming of the pozzolanic gel, therefore enhances the strength $[53,54]$. Some researchers have discussed the effect of adding Nano- $\mathrm{SiO}_{2}$ on fresh and hardened properties of materials. The characteristic of fresh Portland cement paste and mortar was modified by adding Nano- $\mathrm{SiO}_{2}$ [55] as well as for concrete [56]. The strength improved by reducing the porosity when $\mathrm{Nano}-\mathrm{SiO}_{2}$ was added up to a certain percentage [57]. The early compressive strength of concrete made by a high volume of fly ash-cement mix has been influenced positively by adding Nano-SiO 2 [58, 59].

Compressive strength test, XRD, FTIR and SEM were conducted to study the transformation in the structure of geopolymeric binder.

\section{Materials and experiments}

\subsection{Materials}

RM, the primary solid material used in this study, was kindly supplied by Chalco Co. alumina plant in Zibo, Shandong province, China. The DHF86 was used to determine 
Table 1: Chemical composition of RM (wt\%)

\begin{tabular}{lccccccccc}
\hline Sample & $\mathrm{SiO}_{2}$ & $\mathbf{A l}_{2} \mathbf{O}_{3}$ & $\mathbf{N a}_{\mathbf{2}} \mathbf{O}$ & $\mathrm{Fe}_{\mathbf{2}} \mathbf{O}_{\mathbf{3}}$ & $\mathrm{CaO}$ & $\mathbf{K}_{\mathbf{2}} \mathbf{O}$ & $\mathbf{M g O}$ & $\mathrm{TiO}_{2}$ & LOI \\
\hline $\mathbf{R M}$ & 19.41 & 20.77 & 3.78 & 18.15 & 12.11 & 0.14 & 0.62 & 4.29 & 17.00 \\
\hline
\end{tabular}

Table 2: Samples terminology

\begin{tabular}{cccc}
\hline Sample name & $\begin{array}{c}\mathrm{SiO}_{2} / \mathrm{Al}_{2} \mathbf{O}_{3}(\mathbf{S} / \mathbf{A}) \\
\text { (Molar ratio) }\end{array}$ & $\begin{array}{c}\mathrm{Na}_{2} \mathbf{O} / \mathrm{Al}_{\mathbf{2}} \mathbf{O}_{3}(\mathbf{N} / \mathbf{A}) \\
\text { (Molar ratio) }\end{array}$ & $\begin{array}{c}\text { Water/Solid }(\mathbf{W} / \mathbf{S}) \\
\text { (Wt. ratio) }\end{array}$ \\
\hline S3.6 & 3.6 & 1.5 & 0.60 \\
S4.0 & 4.0 & 1.5 & 0.60 \\
S4.4 & 4.4 & 1.5 & 0.60 \\
& & & \\
A1.7 & 4.4 & 1.7 & 0.60 \\
A1.5 & 4.4 & 1.5 & 0.60 \\
& & & \\
W0.60 & 4.4 & 1.5 & 0.60 \\
W0.55 & 4.4 & 1.5 & 0.55 \\
W0.50 & 4.4 & 1.5 & 0.50 \\
\hline
\end{tabular}

the chemical compositions of RM as shown in Table 1. It is a high-precision silicate multi-elements analyzer using element multi-channel color detection technology to detect the different levels of sensitivity and reduce errors. The Sodium hydroxide pellets $(\mathrm{NaOH})$ with purity of $96 \%$ which were added to interact with RM in the ATA process were provided by Sinopharm Chemical Reagent Co., Ltd. Sodium silicate solution (Water Glass - WG) was used as an activator to the solid materials has the following chemical compositions $27.35 \% \mathrm{SiO}_{2}, 8.42 \% \mathrm{Na}_{2} \mathrm{O}$, and $64.23 \%$ $\mathrm{H}_{2} \mathrm{O}$. Nano- $\mathrm{SiO}_{2}$ (non-crystal white powder, $99.8 \% \mathrm{SiO}_{2}$, average particles 30nm and $\mathrm{pH}$ 5-7). The WG was added in different content to improve the geopolymer binder compressive strength.

\subsection{Samples preparation}

The raw $\mathrm{RM}$ soil was dried to constant weight at $105^{\circ} \mathrm{C}$ then was grinded and sieved to pass $0.3 \mathrm{~mm}$ mesh sieve. The dry soil was kept in a glass vacuum desiccator with silica gel to avoid humidity absorption. By using laser granulometer the particle size of RM is range from $1.258 \mu \mathrm{m}$ to $1465 \mu \mathrm{m}$ with a median diameter (d50) of $213.6 \mu \mathrm{m}$.

\subsubsection{Thermal treatment}

Samples were subjected to different temperature, range from 200 to 1000 for 1 hour before adding $\mathrm{NaOH}$. Based on thermal analysis results a specific temperature $\left(800^{\circ} \mathrm{C}\right)$ was chosen to apply the ATA process for making binder samples. Raw RM was mixed with $5 \%$ and $10 \%$ of $\mathrm{NaOH}$ by weight then was calcined at $800^{\circ} \mathrm{C}$ for 1 hour in muffle furnace. These mixes were called RM5 and RM10, respectively. The samples were left inside the furnace to cool down to room temperature.

\subsubsection{Binder mix proportions and samples terminology}

The mix of RM and $\mathrm{NaOH}$ after thermal activation (ATA RM) was grinded and sieved again to pass $0.3 \mathrm{~mm}$ mesh sieve. After thermal activation the particle size is range from 2.04 $\mu \mathrm{m}$ to $198.7 \mu \mathrm{m}$ with a median diameter $42.69 \mu \mathrm{m}$. The molar ratio (S/A) for raw $\mathrm{RM}$ is low, only 0.93 , which is not suitable to prepare a good performance binder. The $\mathrm{S} / \mathrm{A}$ ratios were controlled by adding different amounts of WG to the mix. The WG was mixed with additional water to keep the consistency of samples close as much as possible. The liquid and dry materials were mixed using concrete mixer to synthesize the binder with specific water/solid (W/S) ratio. Three groups of samples were prepared to evaluate the effect of different molar ratios of S/A, N/A and W/S on setting time and compressive strength of the binder. By adding different quantity of WG to RM5 we got three S/A ratios 3.6, 4.0 and 4.4. For RM5 and RM10 the N/A was 1.5 and 1.7. The binder samples were labeled based on the change factor as shown in Table 2. 
Different content of Nano-SiO 2 were added to the mix S4.4 and the samples were expressed by symbols N0.1, N0.2, N0.3, N0.4 and N1.0 for 0.1, 0.2, 0.3, 0.4 and $1.0 \mathrm{wt} \%$ of RM, respectively.

The control sample without ATA was prepared by calcined $\mathrm{RM}$ at $800^{\circ} \mathrm{C}$ without $\mathrm{NaOH}$ (RMC). The same quantity of $\mathrm{NaOH}$ was dissolved in water, mixed with WG, and then was added to the dry RMC to form a binder with targeted W/S ratio. The samples without ATA were not hard enough to be subjected to strength test.

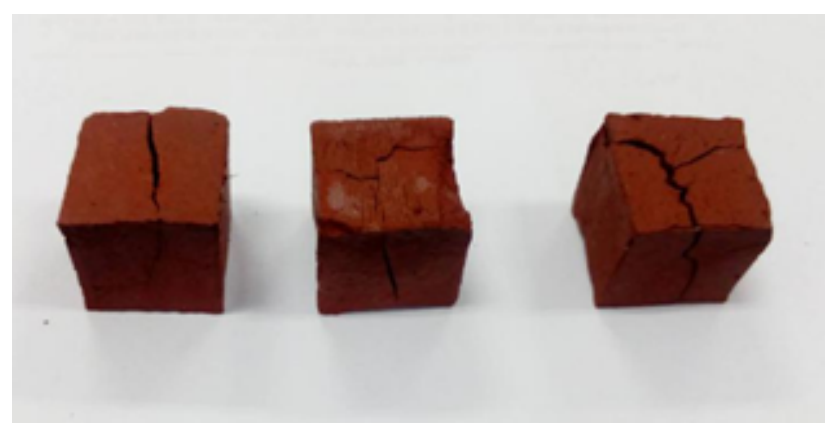

Figure 1: Binder specimens without ATA process

\subsection{Experimental method}

\subsubsection{Thermal analysis}

The as received RM sample was subjected to thermal analysis by thermo gravimetric test using METTLER TOLEDO. The temperature was gradually increased by $10^{\circ} \mathrm{C} / \mathrm{min}$ up to $1000^{\circ} \mathrm{C}$ in air atmosphere.

\subsubsection{Initial and final setting time test}

Initial and final setting time test for samples was conducted using Vicat Apparatus according to ASTM C 191 [60]. The samples mixed with different ratios of S/A, N/A and $\mathrm{W} / \mathrm{S}$ were filled in the cone of the Vicat apparatus and tested to record the initial and final setting time for each sample. The initial time was calculated starting from the moment of adding the liquid activator to dry mix until the needle penetrates down to $5 \mathrm{~mm}$ from the bottom of the mold, while the final time was recorded when the annular attachment failed to make an impression in the sample surface.

\subsubsection{Compressive strength}

To prepare samples for compressive strength test the dry materials and alkali activator were mixed using the electronic mixer for about 3-5 minutes. The mix was poured in copper molds $20^{\star} 20^{\star} 20 \mathrm{~mm}^{3}$ then covered by plastic wrap and left in room temperature $20 \pm 1^{\circ} \mathrm{C}$ for 24 hours. The specimens were cured under $60 \%$ humidity conditions until the test was occurred at 3, 7 and 28 days. The compressive strength test was carried out by 50 Ton compression machine with a loading rate of $0.50 \mathrm{~mm} / \mathrm{min}$ according to ASTM C 109 [61]. All values presented in the current work are an average of six samples.

\subsubsection{Morphology and microstructure tests (XRD, FTIR and SEM)}

The crushed samples of the compressive strength test at 3, 7 and 28 days were grinded and sieved to pass sieve No. $0.3 \mathrm{~mm}$. The XRD patterns were investigated using Bruker D8 diffractometer, the scan was applied between $5^{\circ}$ and $70^{\circ}$ with $0.02^{\circ}$ as a step size and $0.4 \mathrm{~s} / \mathrm{step}$ as a counting time. The machine uses $\mathrm{Cu} \mathrm{K} \alpha$ radiation with wavelength of $\lambda=1.5418 \AA$ at $40 \mathrm{~mA}$ and $40 \mathrm{kV}$.

The FTIR test was performed using AVATAR370 and the samples were prepared as mentioned in XRD test. The resolving power was $4 \mathrm{~cm}^{-1}$, and the scanning frequency was 32 times with a wavelength of $450-4000 \mathrm{~cm}^{-1}$. Samples were tested using attenuated total reflectance.

Small pieces of samples that tested for compressive strength were used for SEM test at 3, 7 and 28 days. Samples were coated with golden conductive coating to prevent charging balance. The test was performed using FEI XL-30 FEG-SEM and a Phillips CM200 (FEI Company, Hillsboro, OR, USA) to study changes in morphology for different samples during the geopolymerization process.

\section{Results and discussion}

\subsection{Thermal analysis and phase transformation}

Figure 2 shows the result of thermal analysis TG and DTG curves for raw RM sample. The constant regression in the TG curve during temperature rising from 20 to 1000 indicates the continuous loss of sample weight as a result of minerals transformation. The four peaks shown in the DTG curve, 283.5, 332, 673 and 897 are considered as an articu- 


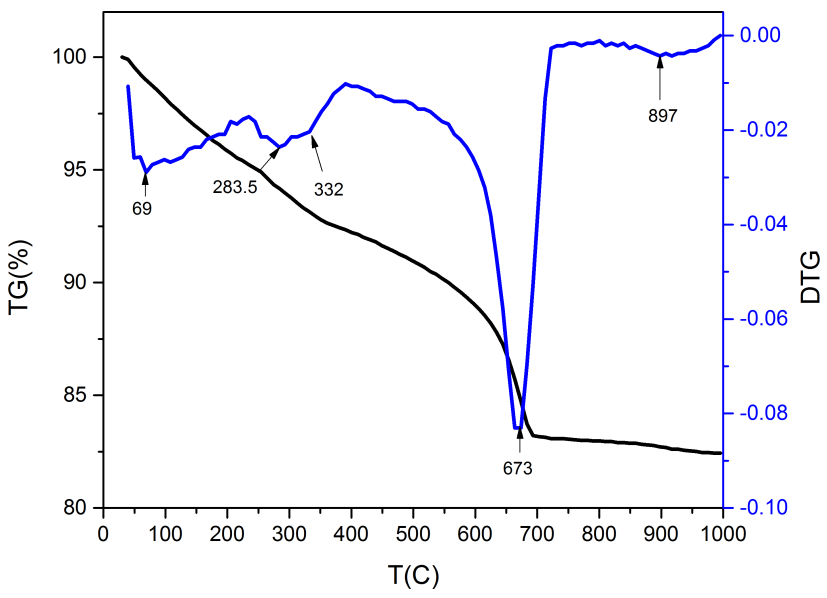

Figure 2: TG and DTG curves of the raw RM sample

lated points in different stages of transformation by dehydration, carbonation and dehydroxylation processes.

As shown in Figure 3 crystalline phases rich in $\mathrm{Al}$, $\mathrm{Ca}$ and Fe were identified from XRD spectra for raw RM such as doyleite, muscovite and calcite. These phases decomposed after calcination in different temperature for 1 hour. At early stage of heating, around $283.5^{\circ} \mathrm{C}$, doyleite decomposed to give a solid $\mathrm{Al}_{2} \mathrm{O}_{3}$. The kaolinite started to increase gradually after $300^{\circ} \mathrm{C}$. Muscovite faded after $500^{\circ} \mathrm{C}$ and by raising temperature together with the kaolinite they transferred to sodium aluminium silicate phase $\left(\mathrm{Na}_{8}\left(\mathrm{Al}_{6} \mathrm{Si}_{6} \mathrm{O}_{24}\right)\right)$. Hematite continued to emerge throughout the calcination process and increased in the advanced stages. The calcite characteristic peak decreased significantly at $700^{\circ} \mathrm{C}$ and disappeared at $800^{\circ} \mathrm{C}$ and the decomposition of calcite contributed to the formation of gehlenite crystalline phase. Nephaline an alkali-rich crystalline phase formed at $800^{\circ} \mathrm{C}$ at $2 \theta$ equals 21 and 23 plus the appearance of some amorphous solids at $2 \theta$ in the range of $28^{\circ}$ to $38^{\circ}$.

\subsection{Effect of alkali thermal activation (ATA) on phase transformation}

The properties of red mud improved significantly with the addition of alkali and calcination at $800^{\circ} \mathrm{C}$ where the crystalline phases decarbonated and dehydroxylated at this temperature. Figure 4 represents the mineralogical analysis for RM before adding $\mathrm{NaOH}$ (RMC) and RM after adding $\mathrm{NaOH}$ (RM5 and RM10) samples at $800^{\circ} \mathrm{C}$ conducted by XRD diffractometer. The result of alkali thermal activation in this study is consistent with previous reserches [49, 62]. More amorphous and glassy phases were emerged as a result of incorporation of alkali and raw

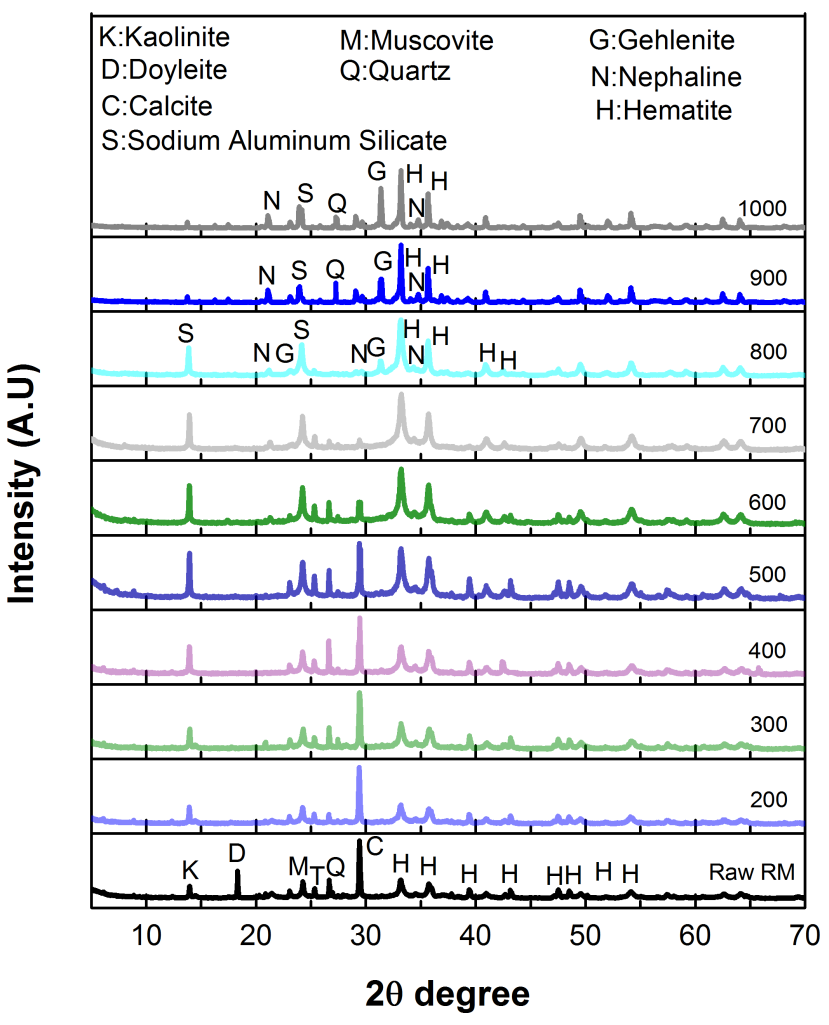

Figure 3: XRD spectra for raw RM and RM samples calcined at different temperatures from $200^{\circ} \mathrm{C}$ to $1000^{\circ} \mathrm{C}$

RM during the ATA process as shown in Figure 4A. The magnified XRD spectra in Figure 4B illustrates the slight hump at $2 \theta$ between $28^{\circ}$ and $38^{\circ}$, which clearly appeared in ATA samples compared to samples calcined without alkali. In addition, when alkali was completely merged with raw RM during the ATA process instead of nepheline new pseudo-crystalline phases with cementitious properties were identified such as hatrurite (Ca3SiO5) and larnite (Ca2SiO4). These phases result in a sclerotic material when mixed with water [49]. It is possible to identify a quaternary phase named sodium magnesium aluminium silicate $\left(\mathrm{Na}_{1.74} \mathrm{Mg}_{0.79} \mathrm{Al}_{0.15} \mathrm{Si}_{1.06} \mathrm{O}_{4}\right.$ - PDF 00-047-1498) that may has similar specs with what known in cement chemistry as $\mathrm{Q}$ compound which has good hydration activity and high compressive strength. All the phases recognized after ATA process were appeared more clearly and in larger quantities in RM5 compared to RM10.

\subsection{Effect of S/A molar ratio on setting time and compressive strength}

The result shown in Figures 5 and 6 presented the setting time and compressive strength for samples made by RM5 and different quantity of WG to study the effect of 


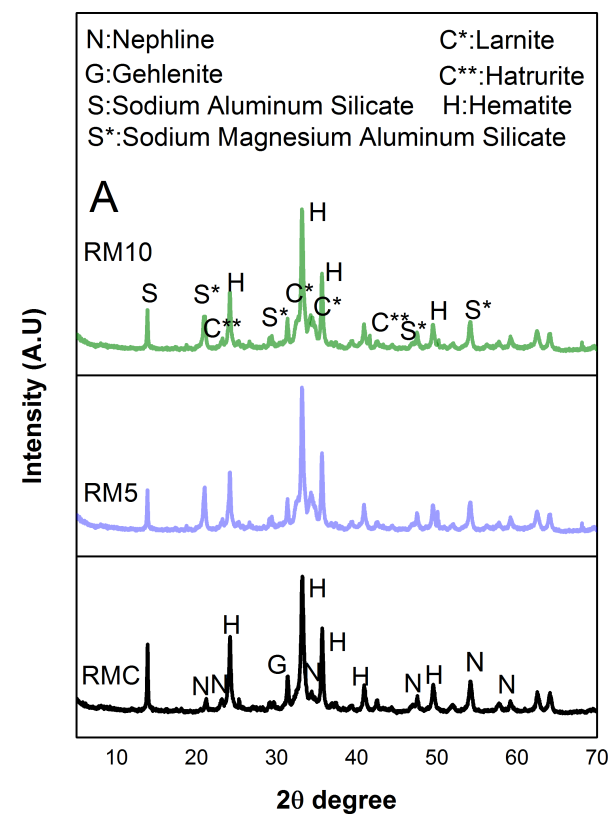

(a)
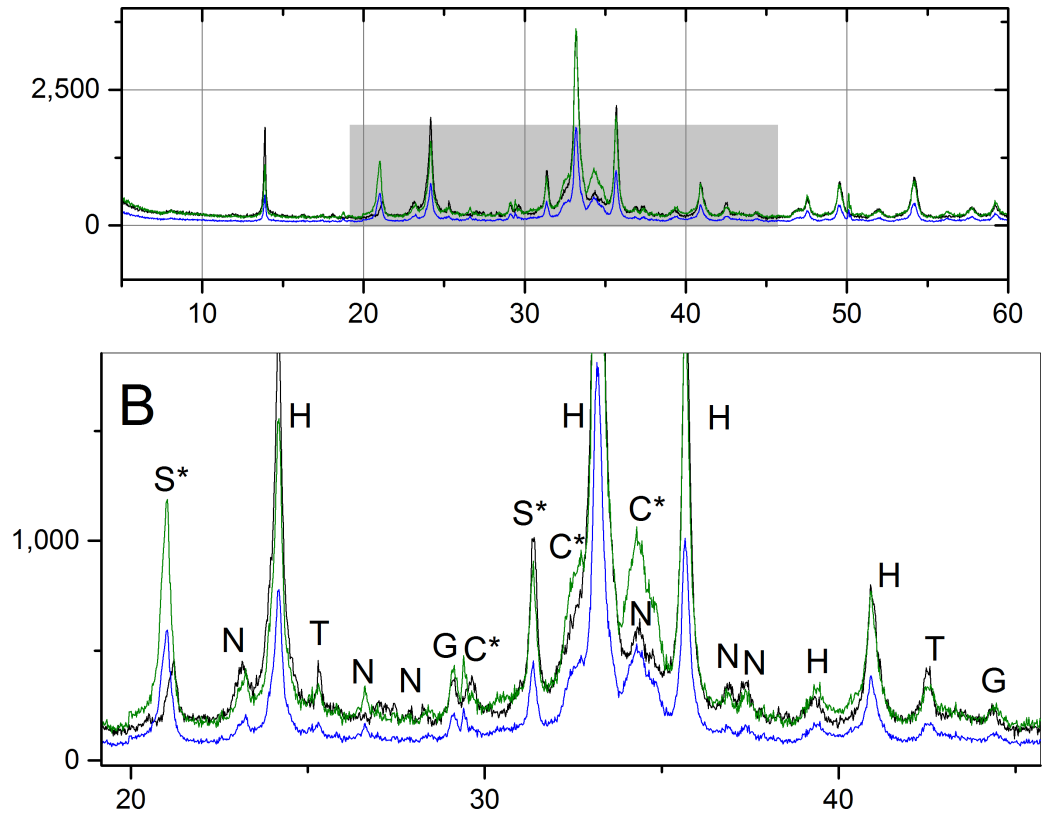

(b)

Figure 4: (A) XRD spectra for RMC, RM5 and RM10 samples calcined at $800^{\circ} \mathrm{C}$; (B) Magnified XRD spectra for RMC, RM5 and RM10 samples calcined at $800^{\circ} \mathrm{C}$. (N:Nephline, G:Gehlinite, H:Hematite, T: Anatase, C*:Larnite, $C^{\star *}$ :Hatrurite, S: Sodium Magnesium Aluminum, $\mathrm{S}^{\star}:$ Sodium Magnesium Aluminum Silicate)

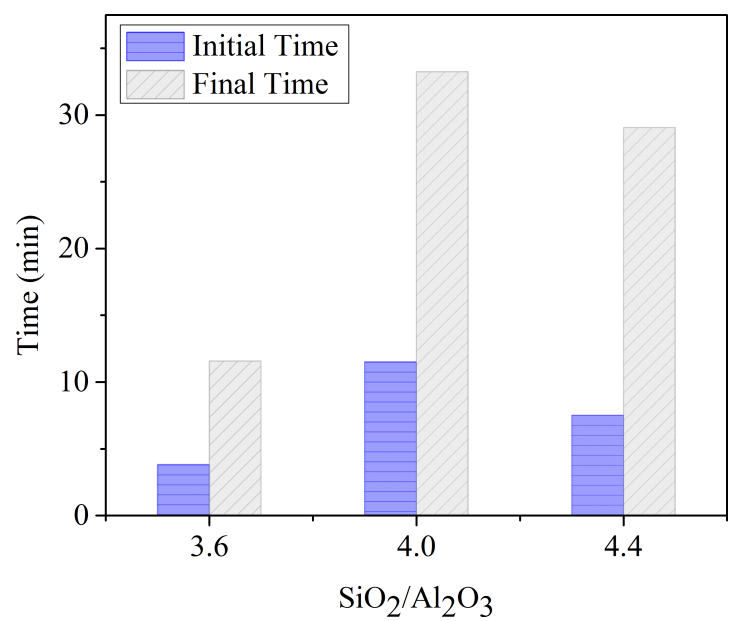

Figure 5: Effect of S/A molar ratio on setting time

S/A molar ratio. By keeping the consistency of samples almost the same, the increase in S/A molar ratio resulted in an increase of the initial and final setting time. However, more increase up to 4.4 caused a relative decrease. The high value of S/A molar ratio in the mixture led to silicasilica reaction, which is relatively slow compared to silicaaluminium reaction, this extended the time of hardening. Regardless the effect of S/A molar ratio in increasing the setting time, the initial time is still considered not long enough for practical applications.

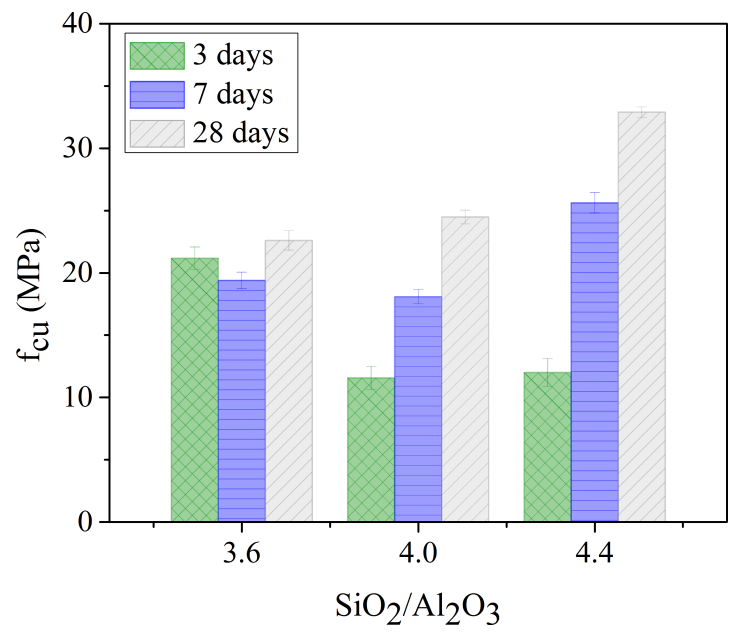

Figure 6: Effect of S/A molar ratio on compressive strength

In Figure 6 samples with lower S/A molar ratio S3.6 recorded a compressive strength up to $20 \mathrm{MPa}$ in 3 days of curing, while the strength in 7 and 28 days remained fairly static. Stability of strength for S3.6 precursors at late ages could be because most of the aluminosilicate gel was formed at an early stage due to the low amount of silica. Other samples with higher S/A molar ratio (S4.0 and S4.4) showed relatively low strength for 3 days, only $10 \mathrm{MPa}$ and $15 \mathrm{MPa}$ respectively. However, for 7 and 28 days the 


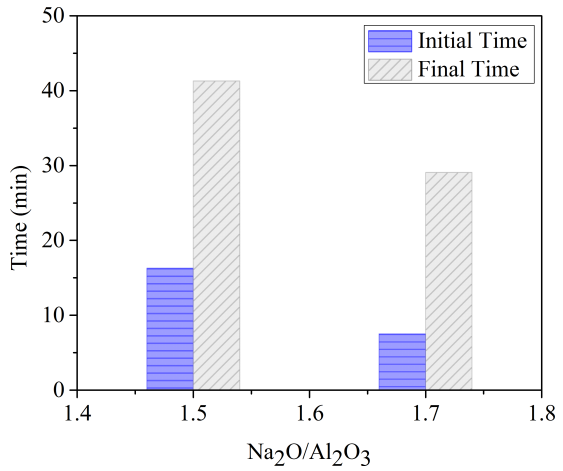

(a)
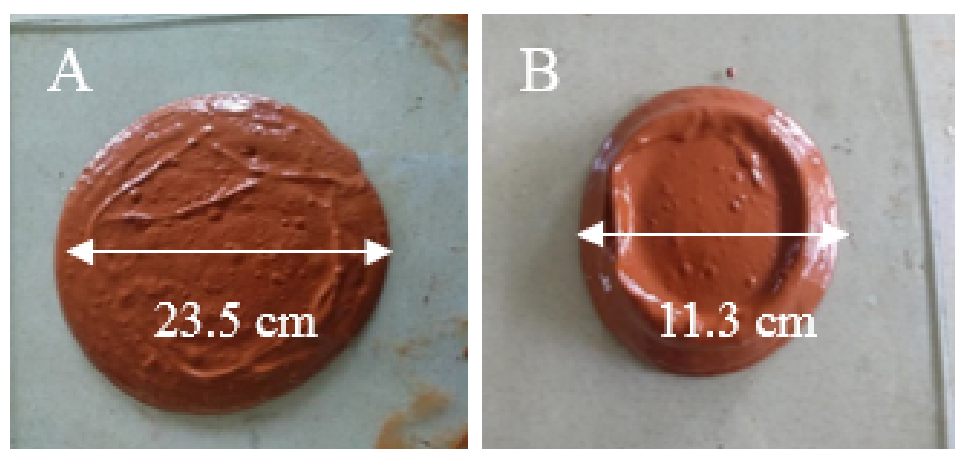

(b)

Figure 7: (A) Effect of N/A molar ratio on setting time; (B) Effect of N/A molar ratio on sample consistency (A: A1.5 and B: A1.7)

strength rose significantly with increasing of S/A, where S4.4 reached $37 \mathrm{MPa}$ in 28 days. As per literature, increasing of S/A molar ratio is responsible of the improvement in compressive strength, where the silicates tend to condensate with each other or with aluminate to form a stiff and stable three dimensional structures, poly (sialate-siloxo) and poly (sialate-disiloxo) comparison to low S/A molar ratio which will form poly (sialate). Since the WG is used to increase the S/A molar ratio, it seems that the silica provided by WG has a strong effect in increasing the compressive strength by increasing the formation of aluminosilicate gel. Results showed that the strength is directly proportional to curing age in samples containing high S/A molar ratio.

\subsection{Effect of N/A molar ratio on setting time and compressive strength}

The samples with different N/A molar ratios 1.7 and 1.5 were prepared by RM10 and RM5 respectively and the result of setting time is given in Figure 7A. The reduction of N/A molar ratio from 1.7 to 1.5 by decreasing the dose of $\mathrm{NaOH}$ from RM10 to RM5 resulted in an increase in the initial and final setting time by $60 \%$ and $30 \%$ respectively. It noticed that increasing the N/A molar ratio caused a quick stiffening and decreased the setting time of the samples. Figure 7B expresses the difference in consistency of samples made by different N/A molar ratios. What mentioned above is supported by the previous studies where the increase of alkalinity adversely affect the physical properties [63].

Figure 8 illustrates the compressive strength of the binder designed using RM10 and RM5 to maintain different N/A molar ratios. Change in N/A molar ratio has considerably affected the long term strength of binders

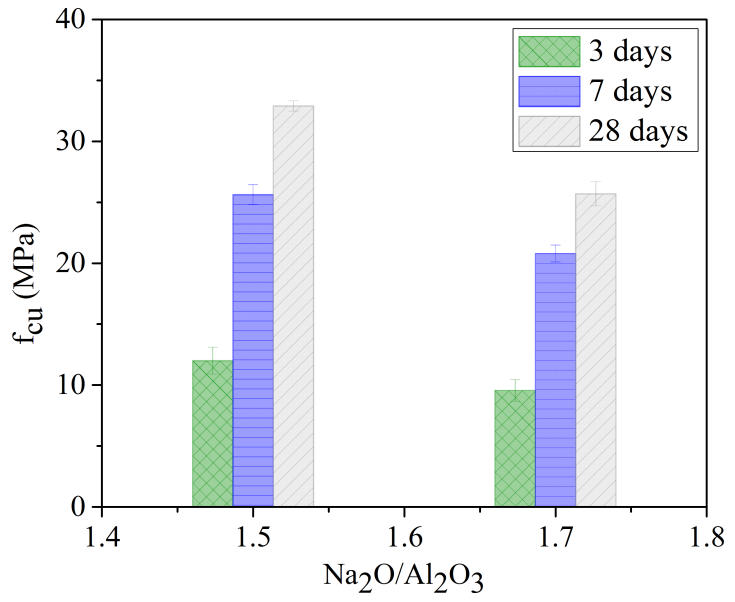

Figure 8: Effect of N/A molar ratio on compressive strength

rather than early strength. The 3 days strength for A1.7 and A1.5 showed the same value, while A1.5 obtained a higher strength than A1.7 at 7 and 28 days. In addition, the high alkalinity led to fast setting where some particles did not completely interact, and this affected the compressive strength. Decreasing the alkaline dose improved the workability of the mix, provided more time for the samples to set and to form more aluminosilicate gel, therefore, increased the strength.

\subsection{Effect of $\mathrm{W} / \mathrm{S}$ ratio on setting time and compressive strength}

Figure 9 shows the effect of mixing the binder with different W/S ratio on setting time. The water quantity in this study was calculated from the sodium silicate, the sodium hydroxide and the additional water. The W0.60 samples showed more workability and longer setting time reached 


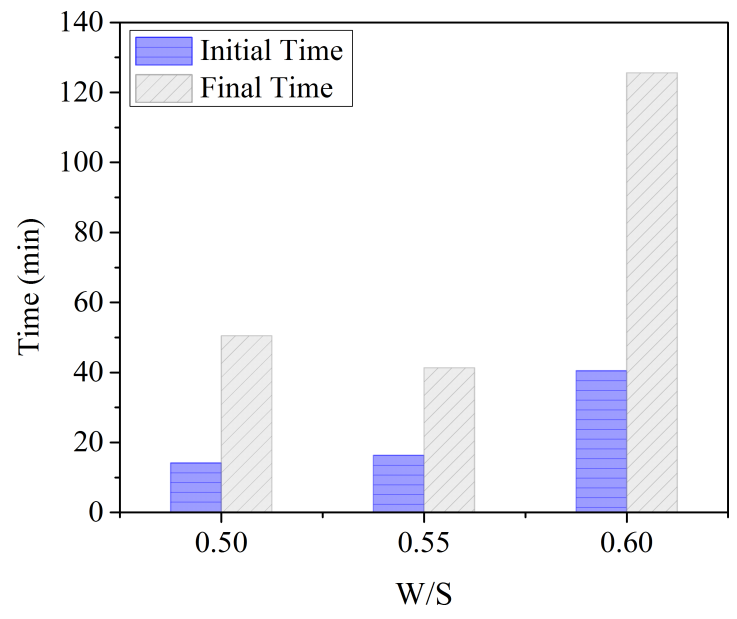

Figure 9: Effect of $\mathrm{W} / \mathrm{S}$ ratio on setting time

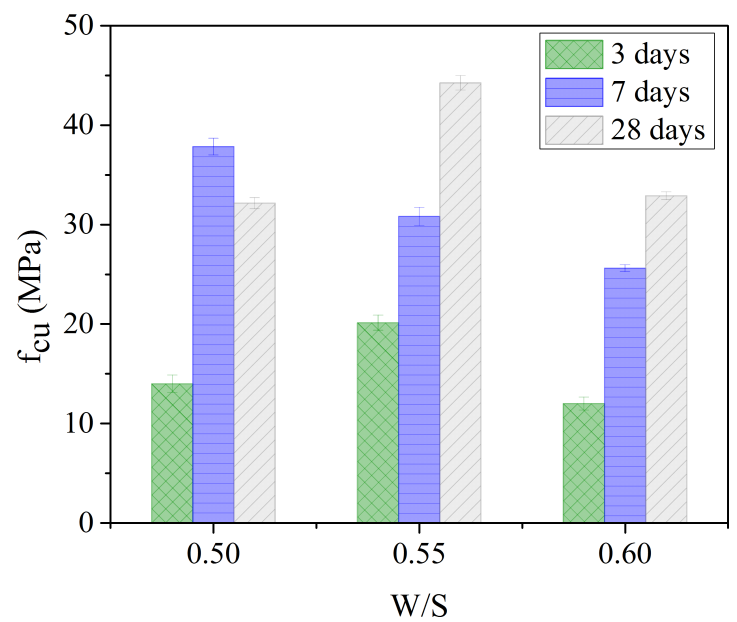

Figure 10: Effect of W/S ratio on compressive strength

to $40 \mathrm{~min}$ and $120 \mathrm{~min}$ for initial and final setting time respectively comparison to other samples. However, S4.4 recorded decrease in compressive strength as shown in Figure 10.

Figure 10 presents the effect of different W/S ratios (0.5, 0.55 and 0.6) on compressive strength. It seems clear that the strength increased slightly when the W/S ratio increased, however adding more water has negatively affected the strength. The reason may will be that the excess water has increased the porosity which caused drop in compressive strength value.

\subsection{Effect of $\mathrm{Nano}^{-\mathrm{SiO}_{2}}$ on compressive strength}

Different content of Nano-SiO 2 were added to sample S4.4 and the compressive strength result for 3, 7 and 28 days is shown in Figure 11. The compressive strength of 3, 7 and 28

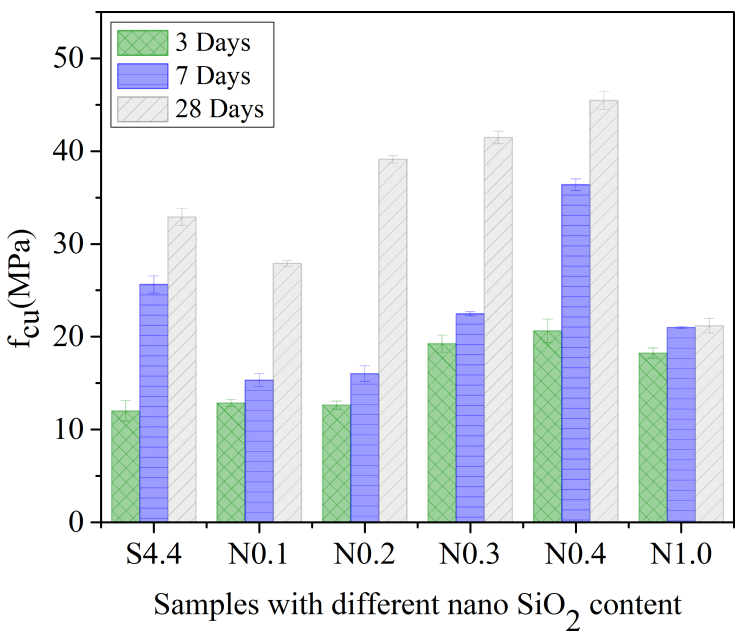

Figure 11: Effect of different $\mathrm{Nano}_{-} \mathrm{SiO}_{2}$ content on compressive strength

days improved by adding Nano-SiO $\mathrm{S}_{2}$ with different content compared to the control sample except for 0.1 and $1.0 \%$. The strength of control sample at 28 days $20.61 \mathrm{MPa}$ increased to $45.43 \mathrm{MPa}$ after adding $0.4 \%$ of $\mathrm{Nano}^{-\mathrm{SiO}_{2}}$. It seems that $\mathrm{Nano}-\mathrm{SiO}_{2}$ reacted with the compounds rich with calcium therefore, it fills the pores and stimulated the formation of aluminosilicate gel beside $\mathrm{CSH}$, leading to higher strength of binder. A significant declination occurred for specimens mixed with 1.0\% Nano-SiO ${ }_{2}$, N1.0. Increasing the dose of Nano- $\mathrm{SiO}_{2}$ created more positive ions that weren't neutralized by negative ions from alkaline, thus it remains unreacted. It deserves to mention that, most samples were suffered from efflorescence due to release of an estimated amount of alkalis, confirming the reason for non-reacted silicate ions especially for samples with $1.0 \%$ of $\mathrm{Nano}-\mathrm{SiO}_{2}$.

\subsection{Microstructure analysis}

\subsubsection{XRD spectra analysis}

Figure 12 presents XRD patterns for RM5 and the three binders made with different S/A molar ratio S3.6, S4.0 and S4.4. The new phase, sodium aluminium silicate created an alkaline environment, these negative charges were balanced by the dissolve $\mathrm{Al}$ and $\mathrm{Si}$ that contribute in geopolymerization [49]. From Figure 12 it is clear that the intensity of the phases decreased with increasing $\mathrm{Si}$ species which have high solubility in low alkaline concentration [64].

Figure 13 shows XRD spectra for the crystalline phases in binder with different $\mathrm{Nano}-\mathrm{SiO}_{2}$ content at 28 days. The phases rich with $\mathrm{Al}$ and $\mathrm{Ca}$ that formed after ATA process 


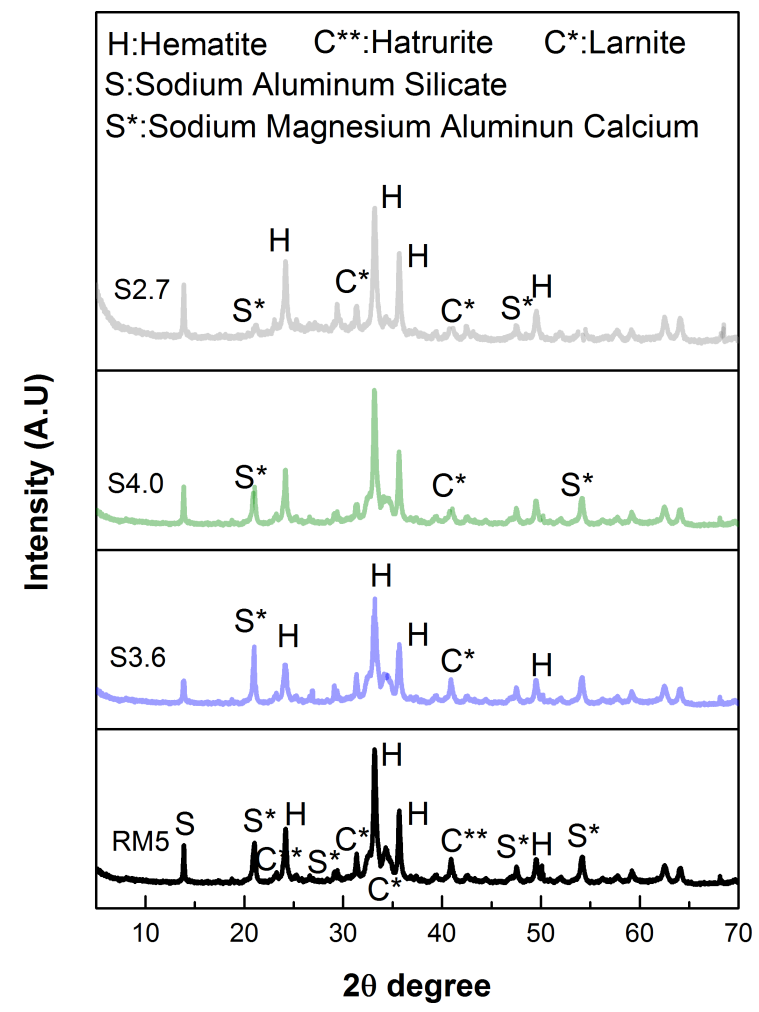

Figure 12: XRD spectra of RM5 and S3.6, S4.0 and S4.4 at 28 days

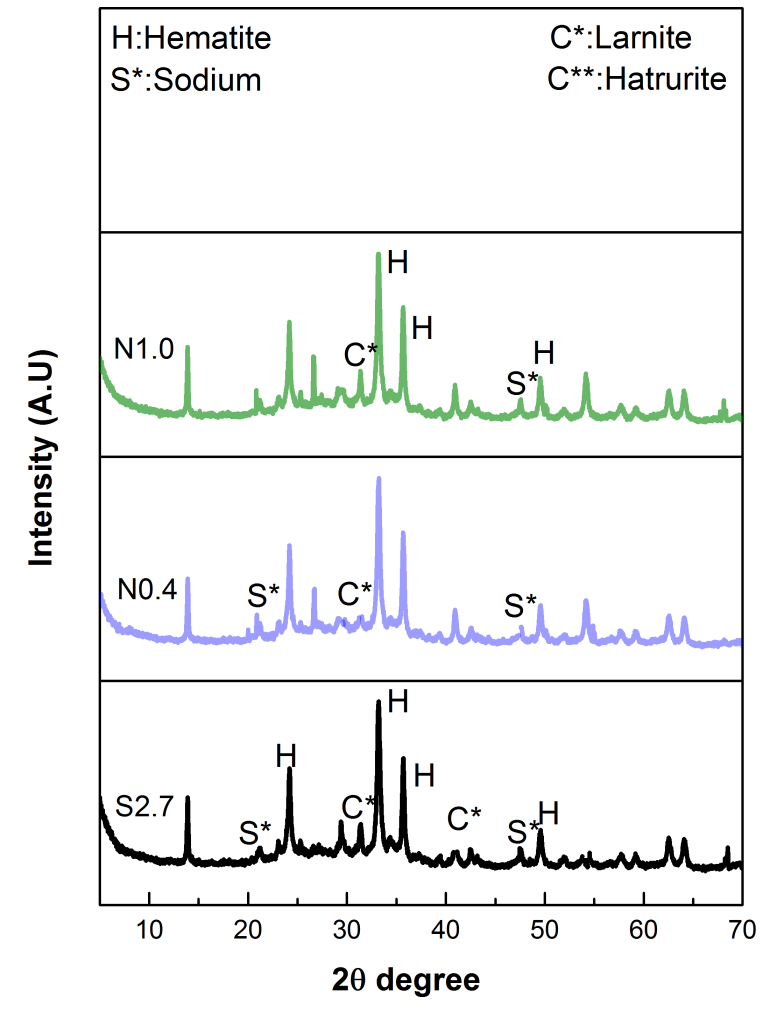

Figure 13: XRD spectra of S4.4, N0.4 and N1.0 at 28 days

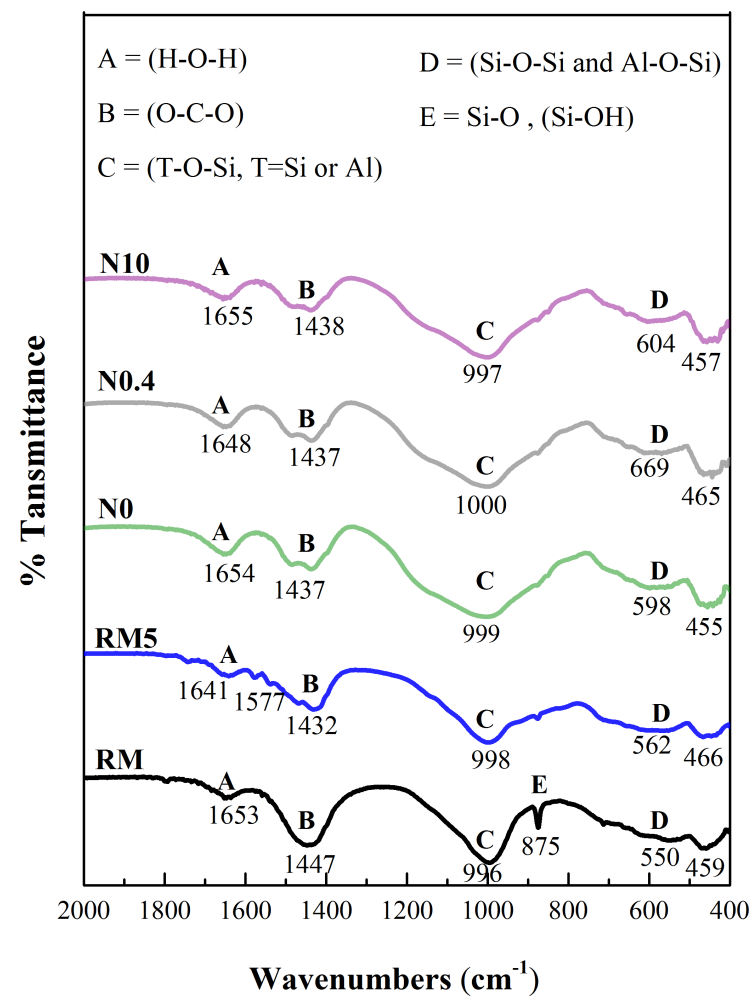

Figure 14: FTIR spectra of RM, RM5, S4.4, N0.4 and N1.0 at 28 days

decreased or disappeared during formation of binder and after adding Nano-SiO${ }_{2}$. The content of the chemical minerals such as hattrurite, larnite and sodium aluminium silicate diminished when Nano $\mathrm{SiO}_{2}$ was added to the mix. This indicates that Nano- $\mathrm{SiO}_{2}$ was helpful to stimulate the geopolymerization process. It is anticipated that most of the calcium dissolved and reacted with aluminosilicate in the high alkaline environment and resulted in high compressive strength. From XRD spectra we observe a plentiful quantity of Hematite. Since the iron in the form of Hematite remained without change after ATA and geopolymerization, this alludes that it has very simple influence in geopolymerization process [65].

\subsubsection{FTIR spectra analysis}

FTIR test was conducted in order to study the phase transformation during the decomposition and geopolymerization processes. Figure 14 shows the FTIR curves. The wavenumbers $1640-1660 \mathrm{~cm}^{-1}$ assigned a bending vibration (H-O-H) of bound water molecules [66]. The large decrease in RM samples treated by ATA indicated the dissociation of the bond due to high heating, it showed up again after geopolymerization inferring hydration and carbonation actions. The same act has been applied to the band 

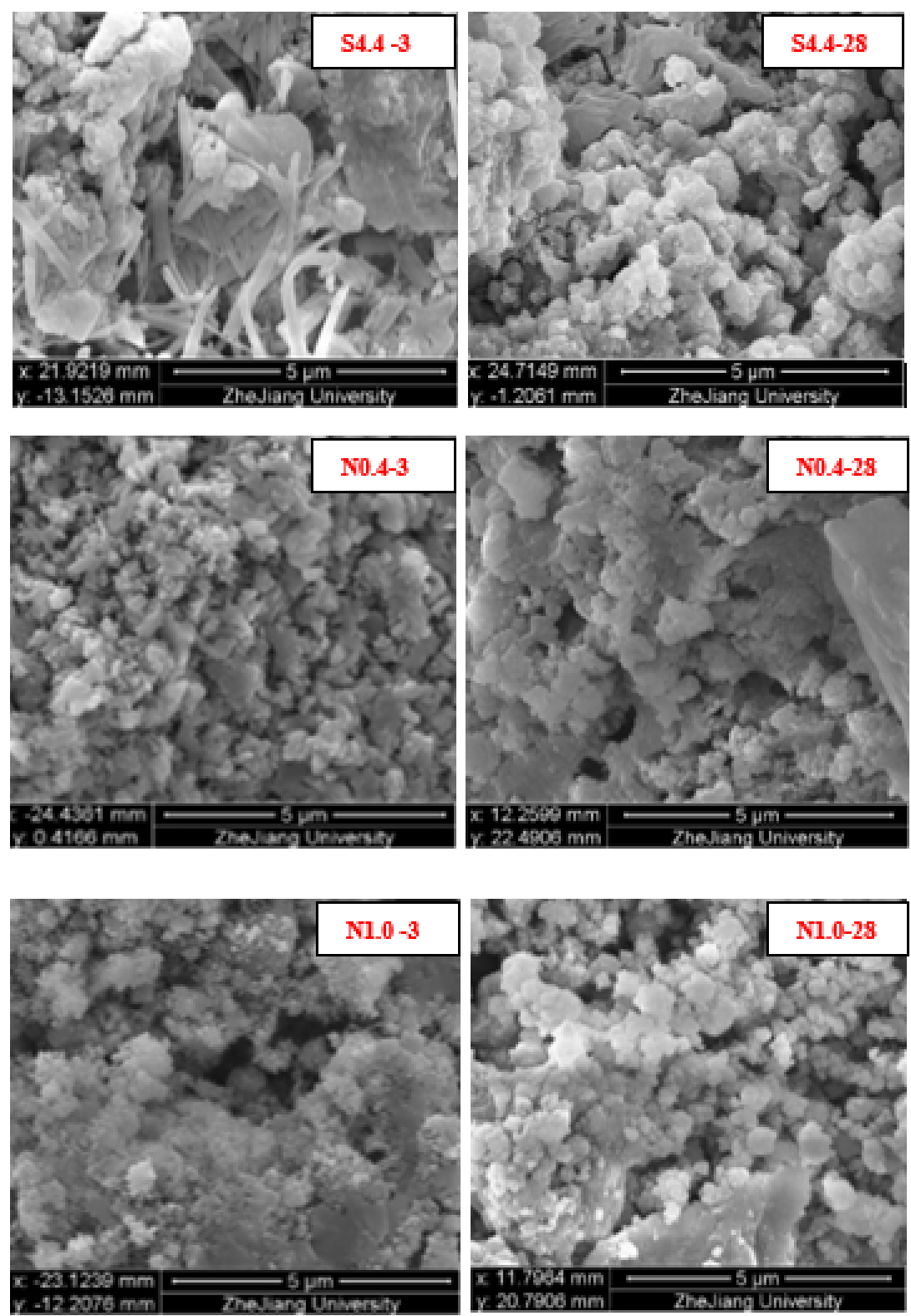

Figure 15: SEM images of S4.4, N0.4 and N1.0 at 3 and 28 days

attributed to stretching vibrations of O-C-O at $1447 \mathrm{~cm}^{-1}$ which decreased to $1432 \mathrm{~cm}^{-1}$ after ATA due to decomposition of RM minerals but increased again for geopolymer precursors. The band formed as a resulting of asymmetrical stretching vibration T-O-Si $(\mathrm{T}=\mathrm{Al}$ or $\mathrm{Si})$ between 1000 $-990 \mathrm{~cm}^{-1}$ wavenumbers increased after ATA and geopolymerization. As known that the increasing of aluminosilicate gel leads to increase the intensity and thus increases chain length. The band attributed to symmetric stretching vibrations of Si-O-Si and Al-O-Si $\left(670-550 \mathrm{~cm}^{-1}\right)$ increased gradually after ATA and geopolymerization but decreased when the Nano- $\mathrm{SiO}_{2}$ is $1.0 \%$. The disappearance of the band at $875 \mathrm{~cm}^{-1}$ caused by bending vibrations of Si$\mathrm{OH}$ indicated that some crystalline phases dissolved too.

\subsubsection{SEM morphology analysis}

Figure 15 shows images of SEM test which implemented to study the morphological transformation of S4.4, N0.4 and $\mathrm{N} 1.0$ at 3 and 28 days. Three different textures appeared in the SEM images of S4.4 samples for 3 days. The bristles indicated that some granules did not interact in the geopolymerization process or the interaction was not complete. The bristles were disappeared in N0.4 and N1.0 at 3 days 


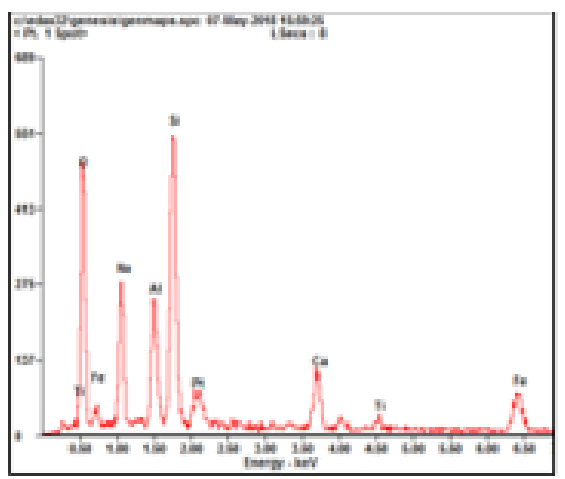

\begin{tabular}{|l|l|l|}
\hline Element & Wt $\%$ & At\% \\
\hline OK & 25.34 & 43.66 \\
\hline NaK & 11.45 & 13.73 \\
\hline AlK & 07.42 & 07.58 \\
\hline SiK & 19.03 & 18.68 \\
\hline PtM & 09.64 & 01.36 \\
\hline CaK & 07.40 & 05.09 \\
\hline TiK & 01.98 & 01.14 \\
\hline FeK & 17.74 & 08.76 \\
\hline Matrix & Correction & ZAF \\
\hline
\end{tabular}
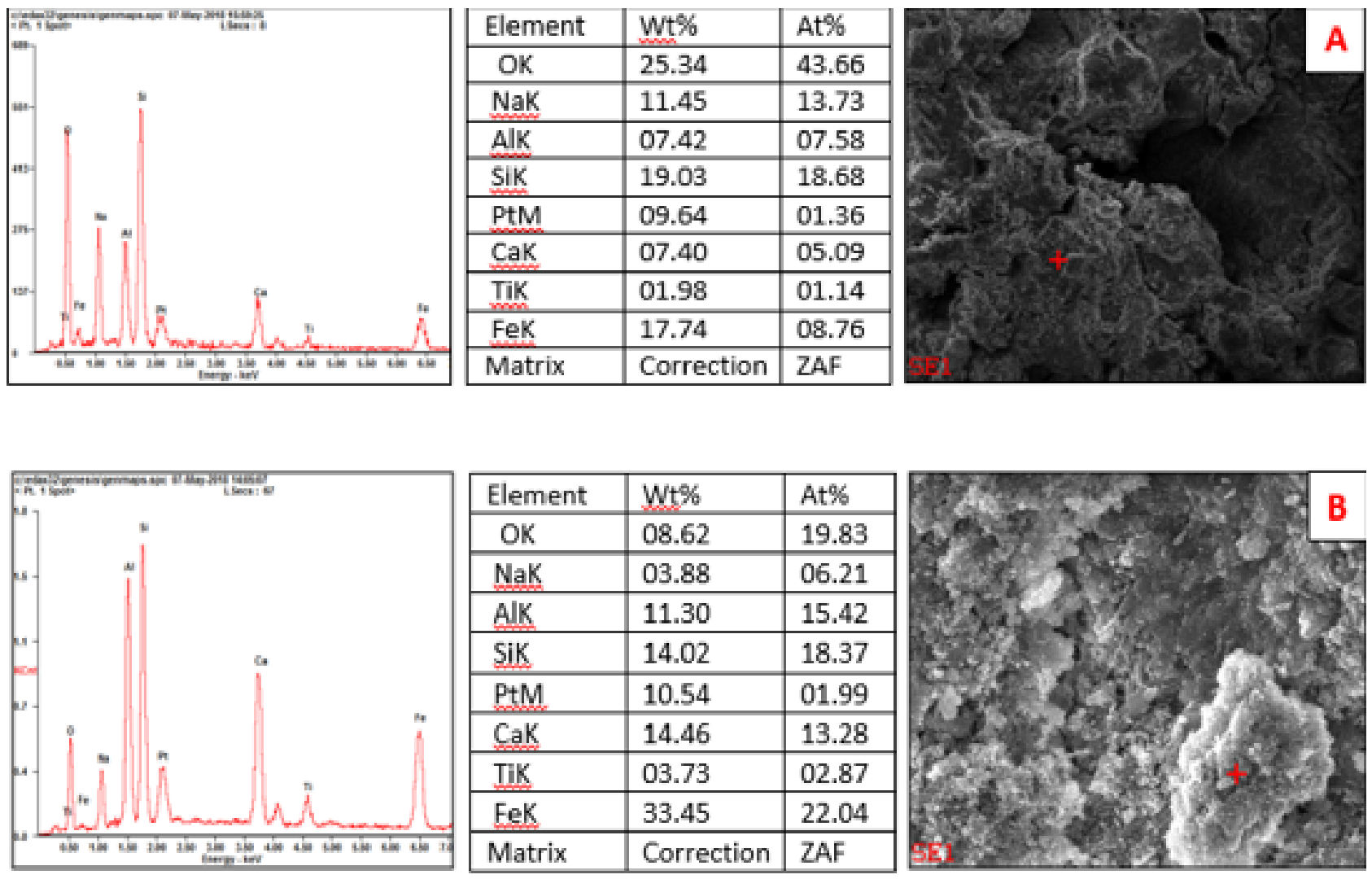

\begin{tabular}{|l|l|l|}
\hline Element & Wt\% & At\% \\
\hline OK & 08.62 & 19.83 \\
\hline NaK & 03.88 & 06.21 \\
\hline AlK & 11.30 & 15.42 \\
\hline SiK & 14.02 & 18.37 \\
\hline PtM & 10.54 & 01.99 \\
\hline CaK & 14.46 & 13.28 \\
\hline TiK & 03.73 & 02.87 \\
\hline FeK & 33.45 & 22.04 \\
\hline Matrix & Correction & ZAF \\
\hline
\end{tabular}
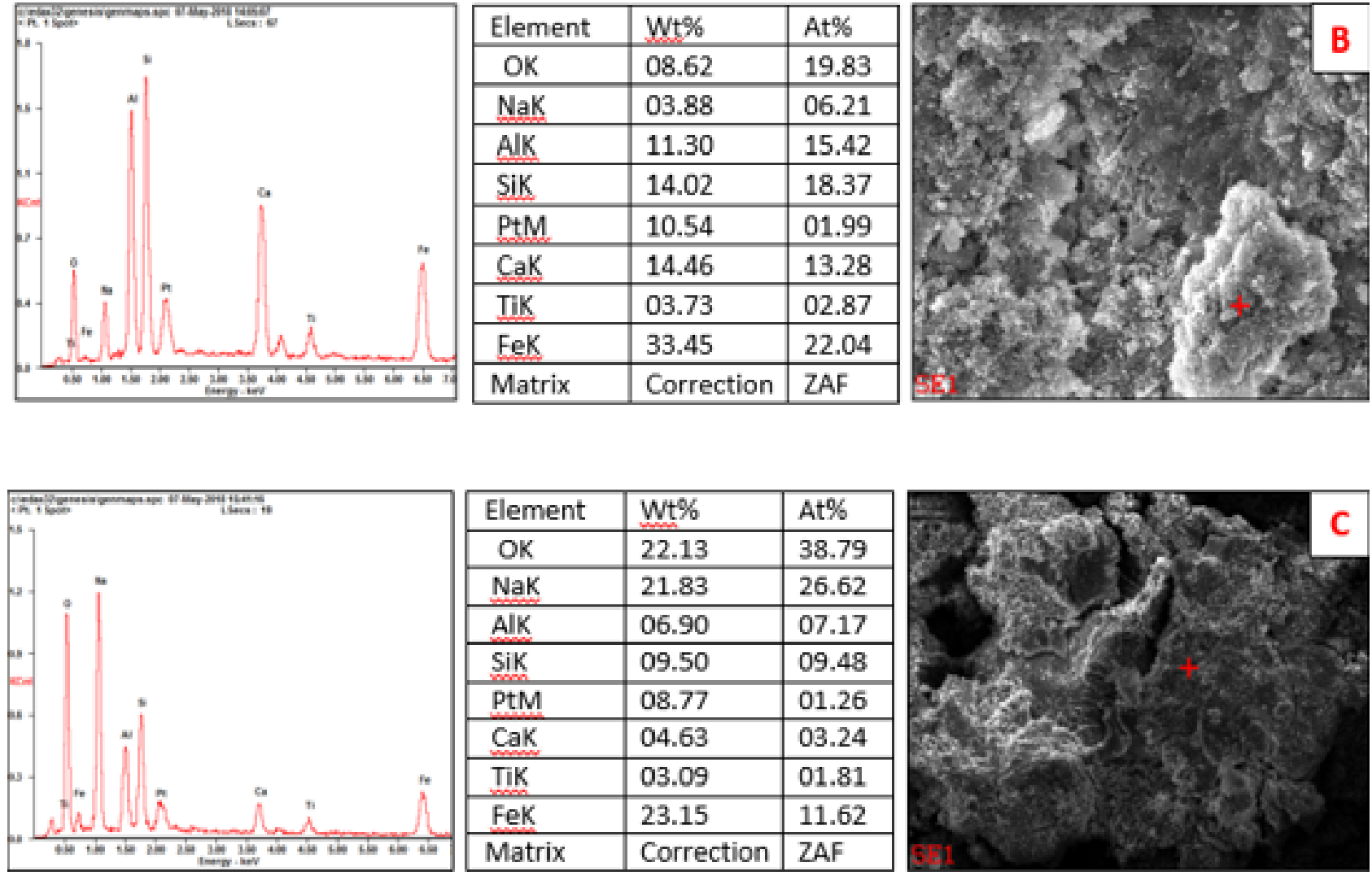

\begin{tabular}{|l|l|l|}
\hline Element & Wt $\%$ & At\% \\
\hline OK & 22.13 & 38.79 \\
\hline NaK & 21.83 & 26.62 \\
\hline AlK & 06.90 & 07.17 \\
\hline SiK & 09.50 & 09.48 \\
\hline PtM & 08.77 & 01.26 \\
\hline CaK & 04.63 & 03.24 \\
\hline TiK & 03.09 & 01.81 \\
\hline FeK & 23.15 & 11.62 \\
\hline Matrix & Correction & ZAF \\
\hline
\end{tabular}

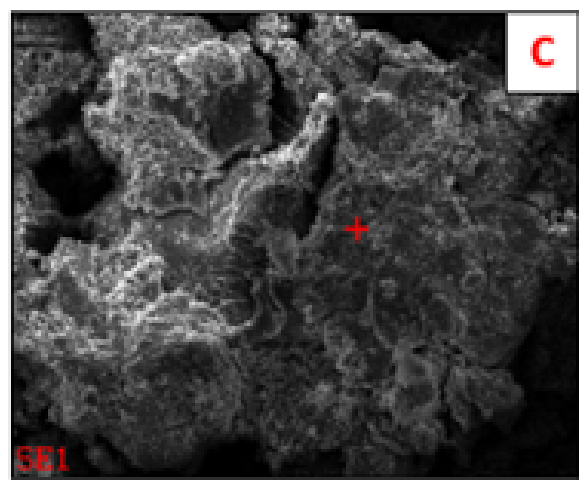

Figure 16: SEM-EDX images of S4.4, N0.4 and N1.0 at 28 days

and replaced by particulates of different intensity and size. For N0.4 samples at 28 days, the particulates have transformed into polished fabric which may indicate the presence of geopolymeric gel plus calcium silicate hydrate. It seemed clear that, for both 3 and 28 days, N0.4 has denser appearance comparison to N1.0, this might be because of the excess amount of Nano-SiO $\mathrm{S}_{2}$ particles which did not participate in the geopolymerization process.

\subsubsection{SEM-EDX analysis}

The SEM.EDX result for S4.4, N0.4 and N1.0 is shown in Figure 16. As seen in Figure 16 the appearance of $\mathrm{Ca}$ in samples reflects the probability of forming $\mathrm{CSH}$ beside the aluminosilicate gel. It is also noticed that the ratio of $\mathrm{Ca}$ in N0.4 is higher than other two samples, this may consider as a reasonable justification of high strength for this sample. 


\section{Conclusions}

This experimental study intended to synthesize a kind of geopolymer binder using RM as primary solid source which was thermally activated by $\mathrm{NaOH}$ and mixed with sodium silicate. In addition, composition optimization and $\mathrm{Nano}-\mathrm{SiO}_{2}$ were used to improve the binder properties. The results are summarized below:

1. Modifying the chemical compositions of RM has a close relationship with the geopolymer binder specifications. Increasing $\mathrm{SiO}_{2} / \mathrm{Al}_{2} \mathrm{O}_{3}$ was found to increase the compressive strength while decreasing $\mathrm{Na}_{2} \mathrm{O} / \mathrm{Al}_{2} \mathrm{O}_{3}$ could improve the workability. The W/S ratio has a significant effect on compressive strength and setting time.

2. The ATA process improved the RM properties and created an alkaline environment that helped decomposing of aluminosilicate and stimulated the emerging of some mineral phases such as Larnite, Hatrurite and Sodium Magnesium Aluminium Silicate which could be key phases in forming the binder. The samples with high strength showed a greater decline in the intensity of these minerals, indicating formation of more binder gel.

3. Adding Nano-SiO 2 with a suitable content could result in a high compressive strength. The Nano-SiO interacted with the minerals in the alkaline atmosphere and contributed to the formation of geopolymer gel and CSH. The compressive strength has increased to be $45 \mathrm{MPa}$ at 28 days by adding Nano- $\mathrm{SiO}_{2}$ with $0.4 \mathrm{wt} \%$ of RM content.

4. However, in this experiment, the addition of $1.0 \%$ of Nano- $\mathrm{SiO}_{2}$ adversely affected the strength of the binder. Increasing Nano-SiO ${ }_{2}$ content may cause an increase of the positive charges unbalanced by alkaline, leading to a reduction in compressive strength, this may can be solved by raising the ratio of alkaline in the mixture. Moreover, all samples were suffered from efflorescence due to the release of an estimated amount of alkalis, confirming the reason for non-reacted silicate ions especially for samples with $1.0 \%$ of Nano- $\mathrm{SiO}_{2}$.

This study will vastly increase utilizing of RM in construction by optimizing composition and adding Nano$\mathrm{SiO}_{2}$ to improve the properties.

Acknowledgement: The authors would like to thank Chalco Company for providing the red mud and the college students Hongming Yu, Juntao Ji, Xuwei Zhang and Lifan Chen for helping to do the experiment for this research.

\section{References}

[1] Poulin É, Blais JF, Mercier G. Transformation of red mud from aluminium industry into a coagulant for wastewater treatment. Hydrometallurgy. 2008;92(1-2):16-25.

[2] Power G, Gräfe M, Klauber C. Bauxite residue issues: I. Current management, disposal and storage practices. Hydrometallurgy. 2011;108(1-2):33-45.

[3] Liu W, Chen X, Li W, Yu Y, Yan K. Environmental assessment, management and utilization of red mud in China. J Clean Prod. 2014;84:606-10.

[4] Smith P. The processing of high silica bauxites- review of existing and potential processes. Hydrometallurgy. 2009;98(1-2):16276.

[5] Liu Y, Lin C, Wu Y. Characterization of red mud derived from a combined Bayer Process and bauxite calcination method. J Hazard Mater. 2007 Jul;146(1-2):255-61.

[6] Liu S, Guan X, Zhang S, Dou Z, Feng C, Zhang H, et al. Sintered bayer red mud based ceramic bricks: microstructure evolution and alkalis immobilization mechanism. Ceram Int. 2017;43(15):13004-8.

[7] Zouboulis Al, Kydros KA. Use of red mud for toxic metals removal: the case of nickel. J Chem Technol Biotechnol. 2007;58(1):95101.

[8] Gräfe M, Power G, Klauber C. Bauxite residue issues: III. Alkalinity and associated chemistry. Hydrometallurgy. 2011;108(1-2):6079.

[9] Zhang M, Zhao M, Zhang G, Mann D, Lumsden K, Tao M. Durability of red mud-fly ash based geopolymer and leaching behavior of heavy metals in sulfuric acid solutions and deionized water. Constr Build Mater. 2016;124:373-82.

[10] Liu W, Yang J, Xiao B. Review on treatment and utilization of bauxite residues in China. Int J Miner Process. 2009;93(3-4):22031.

[11] Liu W, Yang J, Xiao B. Application of Bayer red mud for iron recovery and building material production from alumosilicate residues. J Hazard Mater. 2009 Jan;161(1):474-8.

[12] Mišík M, Burke IT, Reismüller M, Pichler C, Rainer B, Mišíková $\mathrm{K}$, et al. Red mud a byproduct of aluminum production contains soluble vanadium that causes genotoxic and cytotoxic effects in higher plants. Sci Total Environ. 2014 Sep;493:883-90.

[13] Liu RX, Poon CS. Effects of red mud on properties of selfcompacting mortar. J Clean Prod. 2016;135:1170-8.

[14] Liu RX, Poon CS. Utilization of red mud derived from bauxite in self-compacting concrete. J Clean Prod. 2016;112(1):384-91.

[15] Khairul MA, Zanganeh J, Moghtaderi B. The composition, recycling and utilisation of Bayer red mud. Res. Conserv. Rec. 2019;141:483-98.

[16] Lopez E, Soto B, Arias M, Nunez A, Rubinos D, Barral M. Adsorbent properties of red mud and its use for wastewater treatment. Water Res. 1998;32(4):1314-22.

[17] Mesgari Abbasi S, Rashidi A, Ghorbani A, Khalaj G. Synthesis, processing, characterization, and applications of red mud/carbon nanotube composites. Ceram Int. 
2016;42(15):16738-43.

[18] Liu Y, Naidu R. Hidden values in bauxite residue (red mud): recovery of metals. Waste Manag. 2014 Dec;34(12):2662-73.

[19] Klauber C, Gräfe M, Power G. Bauxite residue issues: Il. options for residue utilization. Hydrometallurgy. 2011;108(1-2):11-32.

[20] Mukiza E, Zhang L, Liu X, Zhang N. Utilization of red mud in road base and subgrade materials: A review. Res. Conserv. Rec. 2019;141:187-99.

[21] Hajjaji W, Andrejkovičová S, Zanelli C, Alshaaer M, Dondi M, Labrincha J, et al. Composition and technological properties of geopolymers based on metakaolin and red mud. Mater Des. 2013;52:648-54.

[22] Duxson P, Mallicoat SW, Lukey GC, Kriven WM, van Deventer JS. The effect of alkali and Si/Al ratio on the development of mechanical properties of metakaolin-based geopolymers. Colloids Surf A Physicochem Eng Asp. 2007;292(1):8-20.

[23] Abdel-Raheem M, Santana LG, Cordava MP, Martínez BO. Uses of Red Mud as a Construction Material. AEl. 2017;2017:388-99.

[24] Liu X, Zhang N, Sun H, Zhang J, Li L. Structural investigation relating to the cementitious activity of bauxite residue - Red mud. Cement Concr Res. 2011;41(8):847-53.

[25] Carneiro J, Tobaldi DM, Capela MN, Novais RM, Seabra MP, Labrincha JA. Synthesis of ceramic pigments from industrial wastes: red mud and electroplating sludge. Waste Manag. 2018 0ct;80:3718.

[26] Chen X, Lu A, Qu G. Preparation and characterization of foam ceramics from red mud and fly ash using sodium silicate as foaming agent. Ceram Int. 2013;39(2):1923-9.

[27] Yang J, Zhang D, Hou J, He B, Xiao B. Preparation of glassceramics from red mud in the aluminium industries. Ceram Int. 2008;34(1):125-30.

[28] Yalçın N, Sevinç V. Utilization of bauxite waste in ceramic glazes. Ceram Int. 2000;26(5):485-93.

[29] Erol M, Küçükbayrak S, Ersoy-Meriçboyu A. The influence of the binder on the properties of sintered glass-ceramics produced from industrial wastes. Ceram Int. 2009;35(7):2609-17.

[30] Singh M, Upadhayay SN, Prasad PM. Preparation of special cements from red mud. Waste Manag. 1996;16(8):665-70.

[31] Tsakiridis PE, Agatzini-Leonardou S, Oustadakis P. Red mud addition in the raw meal for the production of Portland cement clinker. J Hazard Mater. 2004 Dec;116(1-2):103-10.

[32] Singh M, Upadhayay SN, Prasad PM. Preparation of iron rich cements using red mud. Cement Concr Res. 1997;27(7):1037-46

[33] Pinnock WR, Gordon JN. Assessment of strength development in Bayer-process residues. J Mater Sci. 1992;27(3):692-6.

[34] Davidovits J. Geopolymers: inorganic polymeric new materials. J Therm Anal Calorim. 1991;37(8):1633-56.

[35] Duxson P, Fernández-Jiménez A, Provis JL, Lukey GC, Palomo A, van Deventer JS. Geopolymer technology: the current state of the art. J Mater Sci. 2007;42(9):2917-33.

[36] Barbosa VF, MacKenzie KJ, Thaumaturgo C. Synthesis and characterisation of materials based on inorganic polymers of alumina and silica: sodium polysialate polymers. Int J Inorg Mater. 2000;2(4):309-17.

[37] Rowles M, O'Connor B. Chemical optimisation of the compressive strength of aluminosilicate geopolymers synthesised by sodium silicate activation of metakaolinite. J Mater Chem. 2003;13(5):1161-5.

[38] Granizo ML, Blanco-Varela MT, Palomo A. Influence of the starting kaolin on alkali-activated materials based on metakaolin. Study of the reaction parameters by isothermal conduction calorimetry. J Mater Sci. 2000;35(24):6309-15.

[39] Duxson P, Provis JL. Designing Precursors for Geopolymer Cements. J Am Ceram Soc. 2008;91(12):3864-9.

[40] Choo H, Lim S, Lee W, Lee C. Compressive strength of one-part alkali activated fly ash using red mud as alkali supplier. Constr Build Mater. 2016;125:21-8.

[41] Chen X, Guo Y, Ding S, Zhang H, Xia F, Wang J, et al. Utilization of red mud in geopolymer-based pervious concrete with function of adsorption of heavy metal ions. J Clean Prod. 2019;207:789-800.

[42] Ye N, Yang J, Liang S, Hu Y, Hu J, Xiao B, et al. Synthesis and strength optimization of one-part geopolymer based on red mud. Constr Build Mater. 2016;111:317-25.

[43] Ye N, Yang J, Ke X, Zhu J, Li Y, Xiang C, et al. Synthesis and Characterization of Geopolymer from Bayer Red Mud with Thermal Pretreatment. J Am Ceram Soc. 2014;97(5):1652-60.

[44] Kaya K, Soyer-Uzun S. Evolution of structural characteristics and compressive strength in red mud-metakaolin based geopolymer systems. Ceram Int. 2016;42(6):7406-13.

[45] He J, Zhang G. Geopolymerization of red mud and fly ash for civil infrastructure applications. Geo-Frontiers 2011: Adv. Geotechn. Eng.; 2011. pp. 1287-96.

[46] He J, Jie Y, Zhang J, Yu Y, Zhang G. Synthesis and characterization of red mud and rice husk ash-based geopolymer composites. Cement Concr Compos. 2013;37:108-18.

[47] Hairi SN, Jameson GN, Rogers JJ, MacKenzie KJ. Synthesis and properties of inorganic polymers (geopolymers) derived from Bayer process residue (red mud) and bauxite. J Mater Sci. 2015;50(23):7713-24.

[48] He J, Zhang J, Yu Y, Zhang G. The strength and microstructure of two geopolymers derived from metakaolin and red mud-fly ash admixture: A comparative study. Constr Build Mater. 2012;30:8091.

[49] Ke X, Bernal SA, Ye N, Provis JL, Yang J. One-Part Geopolymers Based on Thermally Treated Red Mud/ $\mathrm{NaOH}$ Blends. J Am Ceram Soc. 2015;98(1):5-11.

[50] Karimi M, Mirshekari H, Aliakbari M, Sahandi-Zangabad P, Hamblin Michael R. Smart mesoporous silica nanoparticles for controlled-release drug delivery. Nanotechnol Rev. 2016;5(2):195-207.

[51] Rashwan K, Brakke E, Sereda G. Fluorescent labeling of materials using silica nanoparticles. Nanotechnol Rev. 2014;3(6):591-6.

[52] Nakamura M. Biomedical applications of organosilica nanoparticles toward theranostics. Nanotechnol Rev. 2012;1(6):469-91.

[53] Jo BW, Kim CH, Tae G, Park JB. Characteristics of cement mortar with nano-SiO2 particles. Constr Build Mater. 2007;21(6):1351-5.

[54] Phoo-ngernkham T, Chindaprasirt P, Sata V, Hanjitsuwan S Hatanaka S. The effect of adding nano-SiO2 and nano-Al2O3 on properties of high calcium fly ash geopolymer cured at ambient temperature. Mater Des. 2014;55:58-65.

[55] Senff L, Labrincha JA, Ferreira VM, Hotza D, Repette WL. Effect of nano-silica on rheology and fresh properties of cement pastes and mortars. Constr Build Mater. 2009;23(7):2487-91.

[56] Nazari A, Riahi S. The effects of SiO2 nanoparticles on physical and mechanical properties of high strength compacting concrete. Compos, Part B Eng. 2011;42(3):570-8.

[57] Stefanidou M, Papayianni I. Influence of nano-SiO2 on the Portland cement pastes. Compos, Part B Eng. 2012;43(6):2706-10.

[58] Kawashima S, Hou P, Corr DJ, Shah SP. Modification of cementbased materials with nanoparticles. Cement Concr Compos. 
2013;36:8-15.

[59] Qing Y, Zenan Z, Deyu K, Rongshen C. Influence of nano-SiO2 addition on properties of hardened cement paste as compared with silica fume. Constr Build Mater. 2007;21(3):539-45.

[60] Standard Test Methods for Time of Setting of Hydraulic Cement by Vicat Needle.

[61] Standard Test Method for Compressive Strength of Hydraulic Cement Mortars (Using 2-in. or [50-mm] Cube Specimens).

[62] Alp A, Goral M. The Influence of Soda Additive on the Thermal Properties of Red Mud. J Therm Anal Calorim. 2003;73(1):201-7.

[63] van Jaarsveld JG, van Deventer JS. Effect of the Alkali Metal Activator on the Properties of Fly Ash-Based Geopolymers. Ind Eng Chem Res. 1999;38(10):3932-41.
[64] Ye N, Chen Y, Yang J, Liang S, Hu Y, Hu J, et al. Transformations of $\mathrm{Na}, \mathrm{Al}, \mathrm{Si}$ and Fe species in red mud during synthesis of one-part geopolymers. Cement Concr Res. 2017;101:123-30.

[65] Hu Y, Liang S, Yang J, Chen Y, Ye N, Ke Y, et al. Role of Fe species in geopolymer synthesized from alkali-thermal pretreated Fe-rich Bayer red mud. Constr Build Mater. 2019;200:398-407.

[66] Panias D, Giannopoulou IP, Perraki T. Effect of synthesis parameters on the mechanical properties of fly ash-based geopolymers. Colloids Surf A Physicochem Eng Asp. 2007;301(1-3):246-54. 